\title{
The Problem of Leadership in Modern Education
}

\author{
Valentina Dianova \\ Institute of Philosophy \\ Saint-Petersburg State University \\ Universitetskaya Emb.13B, 199034 Saint Petersburg \\ Russian Federation \\ e-mail: v.m.dianova@gmail.com \\ Ludmila Artamoshkina \\ Institute of Philosophy \\ Saint-Petersburg State University \\ Universitetskaya Emb.13B, 199034 Saint Petersburg \\ Russian Federation \\ e-mail: le.artspb@gmail.com \\ Nikita Nogovitsyn \\ Institute of Philosophy \\ Saint-Petersburg State University \\ Universitetskaya Emb.13B, 199034 Saint Petersburg \\ Russian Federation \\ e-mail: nikita.nogovitsyn@gmail.com
}

\begin{abstract}
The article deals with the problem of leadership as the ability to influence people and groups in the organization to achieve their goals. The best-known theories of leadership and concepts of modern leadership are considered, leadership is interpreted as helping other people in their development and self-realization. In education, there are at least three aspects of leadership. The first one is education of leaders as the purpose of the educational process in organizations; the second one is leadership as the principle of management of the leaders of these organizations; the third is the leadership of educational organizations in the market of educational services. The phenomenon of leadership today is relevant in all areas of public life; it is gaining popularity in the field of education. Leadership should be considered not only with reference to the relationship of the leader and the group, but also in relation to the person to himself (personal leadership). In education, leadership is observed in three dimensions: leadership education, leadership of management and leadership of educational organizations in the rankings. The difference between education and other sectors of the economy is its goal-the education of leaders, starting from the preschool level.
\end{abstract}

\section{Introduction}

The issue of leadership, along with the closely associated issue of a leader`s efficiency, is clearly actualized in the contemporary Western literature of late $20^{\text {th }}$ - early $21^{\text {st }}$ centuries. It is usually explained by the change in sociocultural context caused by development of the postindustrial society, intensity of interpersonal communication, challenges set by parties competing in various spheres, a challenge for competitive performance, etc. Leadership is described as a desirable position for a modern person who is supposed to be able to influence other individuals and groups in organizations in order to achieve certain goals regardless of the sphere, be it politics, economy, industry, or culture. There are multiple definitions of leadership: it may be viewed as an ability/feature, activity, or status. Within the realm of education, such definitions of leadership allow to identify this phenomenon in three respective spheres: leader training, leadership qualities of managers, and leadership in educational institutions.

The very idea of leadership is not new. Its sources can be traced to the dawn of the European civilization. Machiavelli wrote about this; he demonstrated that a certain sociocultural context might shape and emphasize corresponding systems of values. As he compared the Middle Ages with their dominant Christian values (such as mercy, sympathy, self-sacrifice, scorn for material wealth; and the belief in salvation seen as the purpose and 
the value that far exceed any social, political, or other mundane purposes, as well as any other economical, military, or esthetical value) with the values of the ancient world that had regained popularity at his time (bravery, service to the society, stability, justice, knowledge and power necessary to achieve the set goals), this Renaissance scholar said that an individual had to choose which of the paths to follow. Machiavelli did not question the legitimacy of either of the values systems and types of morale; instead, he emphasized the possibility that several contradictory values may in fact coexist in the same sociocultural space and, therefore, wrote about the possibility of making a choice. The latter statement is further developed by the modern American scholar Covey, who specializes in the issues of leadership and management. In his book The $8^{\text {th }}$ Habit: From Effectiveness to Greatness, he claims that the book is "devoted to the modest, brave and great among us whose example proves that leadership is a choice and not a position" (Covey 2007). Therefore, a leader is not just anyone (and in fact, not everyone will strive to become a leader); leaders are those who perceive and cultivate their active attitude.

This activity is twofold: activity towards others and activity towards oneself; the latter is perceived as personal or internal leadership. The achievement of this particular quality should be seen as the first step towards leader's qualities. Internal leadership is the basic principle for development of leadership qualities. A person should have a high degree of self-control, be able to be tuned for work, take responsibility for own actions, and have the situation under control. This is the first step that future leaders start their upward movement from, and this should be discussed during the process of upbringing that accompanies education. It is not acquisition of skills for managing other people or for efficient personnel management (these qualities are usually associated with leaders); a true leader should start with self-conquest and self-perfection and only then proceed to the issue of interaction with others. This view of acquisition of leadership qualities, just like the conscious choice of the personal position discussed above, also originates from humanitarian thought. Nietzsche provided well-grounded arguments for this phenomenon, although he did not rely on the present-day concept of leadership. Nietzsche was close to the anthropologic human model where "the creature and the creator are united as one" (Nietzsche $2003)$; in other words, the human's animal nature is linked to their conscious target-setting. He writes about human "material", "clay", "nonsense", and "creator" (Nietzsche 2003). The coexistence of these two ambivalent spheres in the interpretation of a human being implies the inevitability of "waging a war with yourself", learning "the ability to curb yourself", perceiving the necessity to "learn how to see", "learn how to talk and write" (Nietzsche 2003). The solution for this problem is influenced by the formation of a certain hierarchy built of various levels of higher and lower types of people. Nietzsche was concerned about people's reformation, and hence are his recommendations on human improvement that contribute to people's ascension to the superhuman level. Nietzsche views equality as a decline, whereas "the abyss between one human and another, one social class and another social class, the diversity of types, the will to be the unique self and distance yourself from others - that's what I call the pathos of distance characteristic of any powerful epoch" (Nietzsche 2003).

Nietzsche" "pathos of distance" could nowadays be linked with the issue of leadership style. Theoreticians of leadership identify several such styles. The famous psychologist Lewin was the first to identify the three classical leadership styles: authoritarian, democratic, and laissez-faire. The number of acknowledged leadership styles has been gradually growing; the most attractive and studied style at present is the skill of human management based on emotional intellect, which is popularly referred to as emotional leadership. The efficiency of each of these styles is stipulated not only by a leader's psychological features, but also by a company`s specific area of activity. The educational system is closely linked with upbringing, and its staff initially has no standardized structure; therefore, emotional leadership is supposed to be in highest demand in this sphere. In this case, influence on others is associated with such qualities as trust, adoration, enthusiasm, and emotional affectation.

\section{Leadership as part of social interactions}

Social psychology defines leadership as influence of one person on another or on a group of people in order to achieve certain goals (Dinh et al. 2014).

There are multiple theories of leadership. The most popular one is the "trait theory", or "theory of leadership qualities" (Stogdill 1948), which maintains that leaders have a certain set of traits that differentiate them from other people. However, the drawback of this theory is that its authors, who have studied multiple leader types, named such traits as dominance and compliance, ambition and ability for empathic communication, while such contradicting traits can hardly ever be combined in the same person.

Another theory is called the theory of "situational leadership" (Rowold and Schlotz 2009). It implies that a leader acts in accordance with the situation and, in doing this, clearly realizes the "context" rules. 
So, in tune with the theories mentioned above, a leader chooses a leadership style in accordance with the current situation and adheres to either the authoritarian or the democratic leadership style. In other words, a leader tries to be flexible and choose strategies depending on such factors as maturity/immaturity of subordinates, situational pressure, and the leader's personal traits. At this point, a leader either opts for the "discussion" style and suggests solving an issue together, or makes the decision single-handedly, based on own understanding of the situation. The third group of theories describing effective leadership is referred to as "charismatic leadership" (Turner and Haslam 2001). Charisma is usually viewed as bright individuality and influence through the unique personality that can attract and lead people. However, a leader needs three "keys" in order to attract and lead followers:

1) Insight - that is, to be able to shape the image of the desired goal that meets people's expectations (in other words, to draw a picture of the «perfect future", which is a powerful "channel factor" by itself);

2) Key messages - how to get there (what must be done to reach the goal). It is essential not only to demonstrate the goal's magnetism to people (that is, to show the image of the desirable future), but also to define the stages towards the set goal and to demonstrate the essence of each stage. People must realize why this is important to them personally. In this case, individual interests and purposes of staff members will coincide with those of the company;

3) Effective communication, which is a logical consequence of the previous premise. It is the ability to convince and influence. Two factors are essential here: ability to influence with own individuality, personality power, and ability to stimulate people intellectually.

This leads to a logical question: how can we train a leader who will be able to implement innovations in his/her work and successfully implement the skills acquired while learning?

\section{Shaping a leader during an educational process}

Considering the issue of leadership in education, we should start from searching for potential leadership qualities and making them a priority, because they will play a crucial role in shaping an efficient manager. The wish to become a leader is not enough; apart from the inclination, certain abilities would be a great plus. In this connection, psychologists and teachers suggest diagnosing the character of leadership potential, which they define as basic skills that will allow an individual to become an effective leader with less effort or within a shorter time span (Zhivica 2017). In order to diagnose leadership potential, specialists use psychological tests and sociometric techniques; however, role games and business games would be more appropriate in school or preschool settings. These diagnostic procedures allow to differentiate personality skills that are a process by themselves too some extent, because leaders manage themselves, choose or build up a condition or behavior more appropriate for a given situation. Leadership potential implies the ability to understand people, the ability to motivate them and interact with them, which researchers define as relationship skills. Such skills result from the ability to make contact with another person and to encourage this person to perceive problems and objectives - in other words, to fulfil their leadership mission through influencing people. More complex skills, such as strategic thinking or system vision, are acquired later in life and directly contribute to efficient problem solving and the ability to build up a highly functional team.

As we can see, recommendations for self-perfection have gone beyond the reflexive sphere of human selfcomprehension and self-knowledge; they have become popular and are being used en masse. School curriculums now include special subjects that teach basic leadership principles, and teachers explain that these skills are necessary not for survival, but for success and thriving in the $21^{\text {st }}$ century.

Stephen Covey, the American specialist in the leadership theory, has called his method "the leader in me", as he believed that each child has a hidden talent that is waiting to be discovered; in other words, each person has a potential of unused resources (Covey 2015). He described and backed up seven habits of highly efficient people, which could be of great benefit not only for managers, but also for all thinking people. He sees these habits as stimulators for fundamental changes in life.

Habit 1: Be proactive.

I am a responsible person. I take responsibility and make an independent choice about my actions, my attitude to my environment, and my mood. I do not blame others for my mistakes. I demonstrate the right behavior at all times, even when no one asks me for it or no one can see it. Proactive people are aware of their personal responsibility for the outcome.

Habit 2: Begin with the end in mind. Leadership is the same as efficiency: it is the vision that will be implemented. I plan in advance, and I set goals. I only do things that make sense and may have a positive impact. 
I am an integral part of my class. I contribute to my school's mission and vision. I do my best to be a good citizen.

Habit 3: Put first things first. I allocate my time to the most important activities. This means that I say no to the activities that I know should not be done. I set priorities, I schedule my actions, and I keep to this schedule. I am disciplined and well-organized.

The first three habits are viewed as a personal victory, a self-victory. The habits that follow imply personality development during interaction with others.

Habit 4: Think win-win. Many people have been told since their childhood years that they should "win or lose", that is, only one party may become the winner. It also involves school exams, parents ' appraisal of their success, constant comparisons with other people, and school reports. As a result, children are raised to think that there is only one cake for the winner at the end of the track. This restricts the ability to rejoice at others' achievements and even cultivates the ability to feel happy about other people's failure. This results in "shortage thinking". I, on the contrary, advocate for "abundance mindset". I welcome other people's success; I admit that people do not achieve success on account of others. If a conflict arises, I look for a mutually beneficial third alternative, I realize that there are win-win solutions, and I look for such solutions.

Habit 5: Seek first to understand, then to be understood. I am attentive to ideas and feelings of other people. I try to look at events from their perspective. I listen to people and do not interrupt them. I am confident at expressing my ideas. When I talk to people, I make eye contact with them. When we feel that someone is sincerely trying to see our point of view, we acknowledge and share their openness, readiness for negotiation and search for mutually beneficial solutions.

Habit 6: Synergize. I appreciate strong sides of other people and learn from them. I get on well with people, even with those who are different. стремиться к синергии. I am a successful team player. I welcome other people's ideas when I solve problems, because I know that collaboration will lead us to a better solution than the one we could have found while working individually. The nature is synergic; each living thing or plant is interconnected with others.

The final habit links all the previous six together; it unites them together and heralds the common victory.

Habit 7: Sharpen the saw. There is a metaphor about a woodcutter who works hard to fell a tree. He should obviously sharpen his saw, but when someone asks him why he wouldn't stop and sharpen his saw, he says, "I can`t be interrupted - I'm too busy sawing the tree." This is a warning. As we get too involved in finding a solution to a problem, we ignore basic things:

- Physical I" requires exercise, a balanced diet, and stress management skills;

- Social and emotional I" is linked to others through help, sympathy and synergy, and is a source of confidence;

-"Spiritual I" requires to clarify and confirm our values and adherence to them through learning, meditation, and reflection;

-"Mental I" is shaped by a person`s education through reading, planning, writing, and a harmonious program for sustainable personality development.

This list of habits demonstrates that the author views leadership not only as related to himself or herself (personal leadership), but also from the perspective of interaction between a leader and a group. This extended definition of leadership results from the processes of modernization that are active mostly in the West and confirm the activist position in that area. In 2004, Covey published a sequel to "The Seven Habits of Highly Effective People" titled "The $8^{\text {th }}$ Habit: From Effectiveness to Greatness" (Covey 2007). Covey saw the primary challenge of the modern world in finding our own voice and in encouraging others to look for their own voices. By stating this, he argues that the modern reality requires serious reforms in thinking: a new way of thought and a certain set of skills.

\section{Modern forms of communication and their influence on the educational process}

Approaches to leadership have radically changed, and this is caused not only by changes in management, but also by changes in culture as the society is progressing from informational to post-informational society. The general outline of the future society can be seen as we consider the "post-"condition. It is obvious that if humankind used to invest all its effort in fighting for food and habitation (although many people still have to fight for them), more and more people of today are struggling not for survival, but for prosperity. Many researchers who are considering the future that awaits us after the era of information and technology talk about the increased attention to various forms of creativity in everyday practices, both social and individual. The new market - the "market of dreams" or "market of emotions" - is emerging (Jensen 2004). The author describes six 
new markets: 1. Adventures for sale; 2. Market of spiritual affinity, friendship, and love; 3. Market of care; 4. The Who-am-I market; 5. Market of peace of mind; 6 . Market of creeds. Taken together, these are the crucial aspects of the dream society. The informational society was driven by informational technologies; in the dream society, all activity will be driven by stories and emotions rather than data. Scientists of the Copenhagen Futurology Institute were studying sources for the consumption growth in the future; their conclusion was that the future consumption would be non-material for the most part. This means that any company will find it crucially important to control the growth of these new emotional markets. That is why emotions are gradually becoming determiners of the future market. The goods (their content or use) will be of secondary importance; they will go in a set with a story of some kind. "Anyone who wants to succeed in the future market has to learn the art of storytelling. A story is the heart of the matter» (Jensen 2004).

The society of the advancing future is shaping a new attitude to labour. The informational society and introduction of new technologies have contributed to these changes. Labour is no more associated with a certain "workplace", which eventually changes the very character of the social hierarchy: it is no longer associated with the habitual position of a manager's superiority over subordinates. It is more common that the "managerial" position has to be backed up by leadership qualities. This is closely linked with a product s promotion because the key to successful promotion is a non-trivial development strategy and creation of a non-conventional brand. What is more, the success of the new strategy lies in creation of a unique brand. The strategy is based not only on a leader's broad thinking, but - more importantly - on fertile imagination, the use of non-trivial ideas in the company`s brand and image.

The manner of collective work is also changing. As the demand for "products of imagination" is constantly increasing, there is a growing need for the increased share of individual initiative shown by creative staff members; consequently, the staff members need more free time and space to "nurture" this initiative.

Therefore, the dominating mode of relationship between the leader and staff is not hierarchy, but rather partnership and friendship. Such leadership allows for emotional fulfilment for all parties in such relationship.

One attribute of leadership (achievement of a leading position) is an ability to elaborate and support new symbols and rituals that accompany them. Such formation of leadership is demonstrated in the fiction film Dead Poets Society.

Leadership implies the skill of creative use of time/space. The modern city culture has more and more evidence of certain organizational forms for such "creative spaces". For example, France has about 50 cafesphilos. These are places where a philosopher can start put forward a topic and host a subsequent discussion, for example, about the correlation between good and evil, about eternity, or about people's attitude to the nature. A group of interested listeners will start a discussion that anyone is welcome to join. Obviously, this idea originates from France, because this country has a special form of spiritual affinity, which is France`s long-term glorious tradition.

We can witness specific processes in other city spaces. For example, the creative space Kuluary appeared in St.Petersburg, near the State University and the Library of Academy of Science. It hosts philosophic disputes where young philosophers who have not yet received formal degrees can participate on equal grounds with renowned scholars. In such setting, the leader is chosen as a result of direct personal impact and subsequent acknowledgment, and the leadership here is always confirmed "here and now".

\section{Conclusions}

Educational strategies are elaborated on the joint basis of theory and practice. The modern educational process implies simultaneous use of the cognitive (formation of knowledge, mastering the methods of cognitive activity), affective (development of feelings and personality`s emotional sphere), and conative (developing self-regulation reflected in actions and chosen mode of behavior) forms of teaching. Formation of a student's leadership qualities is an essential part of this process.

Leadership is a personal strategy. There is a popular belief that leadership is based on three factors: ambition or internal impulses, competences or experience, and internal holism or moral principles. In troubled times, we should remember about the danger of choosing a leader with ambition and competence, but without moral rectitude. We believe, therefore, that high moral qualities should be a first step in the upward movement towards leadership in education and upbringing. 


\section{References}

Charms R, Personal Causation: The Internal Affective Determinants of Behavior, $1^{\text {st }}$ edn. (Routledge: New York, USA, 1983), $416 \mathrm{p}$.

Covey SR, Eighth skill from efficiency to greatness, $1^{\text {st }}$ edn. (Alpina Business books: Moscow, Russia, 2007), $500 \mathrm{p}$.

Covey SR, Seven skills of highly effective people, $1^{\text {st }}$ edn. (Piter: Saint-Petersburg, Russia, 2015), 424 p.

Dinh JE, Lord RG, Gardner WL, Meuser JD, Liden RC, Hu J (2014) Leadership theory and research in the new millennium: Current theoretical trends and changing perspectives. The Leadership Quarterly 25: 36-62. doi: 10.1016/j.leaqua.2013.11.005

Jensen R, Dream Society. How the coming shift from information to imagination will transform your business, $1^{\text {st }}$ edn. (Lite Book: St.-Petersburg, Russia, 2004), 37p.

Machiavelli N, The Prince, $7^{\text {th }}$ edn. (Hackett Pub. Co: Indianapolis, USA, 2008), $451 \mathrm{p}$.

Marshall M, Understanding Media: The Extensions of Man, $3^{\text {rd }}$ edn. (Gingko Press: Hamburg, Germany, 2003), $72 \mathrm{p}$.

Nietzsche F, Beyond Good and Evil, $1^{\text {st }}$ edn. (Penguin Classics: London, UK, 2003), 352 p.

Rowold J, Schlotz W (2009) Transformational and Transactional Leadership and Followers, Chronic Stress. Leadership Review 9:35-48.

Stogdill RM (1948) Personal factors associated with leadership: A survey of the literature. Journal of Psychology 25: 35-71. doi:10.1080/00223980.1948.9917362

Turner JC and Haslam SA (2001) Social identity, organizations and leadership. Groups at work: Advances in theory and research. Personality and Social Psychology Bulletin, 20: 25-65. doi:10.1177/0146167294205002

Zhivica OV, Liderstvo. Uchebnik dlya studentov vysshih uchebnykh zavedeniy, izuchayschikh specialnosti Psikhologiya, Menedgment Organizaciy, Predprinimatelstvo, $1^{\text {st }}$ edn. (Sinergia: Moscow, Russia, 2017), 44p. 